\title{
The Use of APS Thermal Barrier Coatings in Corrosive Environments
}

\author{
Jonathan Wells ${ }^{1} \cdot$ Neil Chapman ${ }^{1} \cdot$ Joy Sumner $^{2}$ • \\ Paul Walker ${ }^{1}$
}

\begin{abstract}
Thermal barrier coatings (TBC) can be used to reduce the metal temperature of gas turbine blades enabling higher $\mathrm{Cr}$ alloys (lower strength) to be used when gas turbines are to be used in corrosive environments (where hot corrosion resistance is required). However, the TBC must also be resistant to the corrosive environment and remain attached to the blade. A $1000 \mathrm{~h}$ test to evaluate air plasmasprayed (APS) TBC adhesion to a low-pressure plasma-sprayed CoNiCrAlY bond coat (with and without through thickness cracking) under hot corrosion conditions at $850{ }^{\circ} \mathrm{C}$ has been carried out. The APS TBC significantly reduced the hot corrosion rate of the CoNiCrAlY; however, delamination cracking occurred with a thinner thermally grown oxide than would be expected from isothermal and cyclic oxidation testing.
\end{abstract}

Keywords APS TBC · Hot corrosion · Spallation

Joy Sumner

j.sumner@cranfield.ac.uk

Jonathan Wells

jonathan.wells@siemens.com

Neil Chapman

chapman.neil@siemens.com

Paul Walker

paul.m.walker@siemens.com

1 Siemens Industrial Turbomachinery Limited, Ruston House, PO Box 1, Lincoln, Lincolnshire LN5 7FD, UK

2 Cranfield University, College Road, Cranfield, Bedfordshire MK43 0AL, UK 


\section{Introduction}

To improve the strength of nickel-based superalloys, there has been a trend to reduce the Cr levels within the alloys [1]. With some of these alloys also having an increase in $\mathrm{Al}$ content, the high-temperature oxidation resistance has also improved. However, there has been a corresponding drop in hot corrosion resistance. This has caused problems in the under platform region of hot section rotor blades (due to type II hot corrosion), and makes designing for corrosive sites more difficult. One solution is to use alloys with higher Cr contents (which are known to have better type II hot corrosion resistance [2]), and lower creep strength, but to add a TBC over gas-washed surfaces to reduce the metal temperature of the aerofoil (allowing a higher creep stress to be tolerated by the metal at the lower temperature). The aerofoil would be exposed to higher surface temperatures than the blade root, and hence, any TBC on the aerofoil would need to remain attached to the component in type I hot corrosion environments.

Research into hot corrosion of TBCs [3] has identified different degradation mechanisms, many of which concentrate on the interaction between deposits, the gaseous atmosphere and the ceramic layer. Mitigations include using glazing or seal coats to prevent deposit interactions, using alternative stabilizers for zirconia, and alternative ceramic compositions. Further changes to the ceramic layer composition are also being considered to prevent interactions with calcium-magnesiumalumino-silicate (CMAS)-type deposits at higher temperatures [4]. However, new coating compositions need significant amounts of design data to be generated prior to use, which could take years, and may increase the cost of components.

In addition to the presence of the hot corrosion environment, as the components in the gas turbines can be rotating, they can experience high localized surface strains. These strains could lead to cracks forming in a ceramic TBC. Minor amounts of foreign object damage (FOD) can also occur, which may also lead to cracking of a TBC. Therefore, a TBC must show resistance to spallation in a corrosive environment, even when cracked. As such, this paper considers how cracking in a TBC would affect the life of the coating system as well as considering the possible limits that operating in a corrosive environment may have on the system's use.

\section{Experimental Procedures}

\section{Samples}

Two sample types were used for this work-flat plates of alloy Haynes 230 (approximately $30 \mathrm{~mm} \times 30 \mathrm{~mm} \times 2 \mathrm{~mm}$ ) that were coated on one side and curved samples of IN6203. A photograph of the curved sample is shown in Fig. 1. The curved sample was designed to represent typical radii encountered on hot gas path blades and vanes - on one edge the radius of curvature was $1.5 \mathrm{~mm}$, and on the other edge the radius of curvature was $0.35 \mathrm{~mm}$. Two coatings were used: an low 

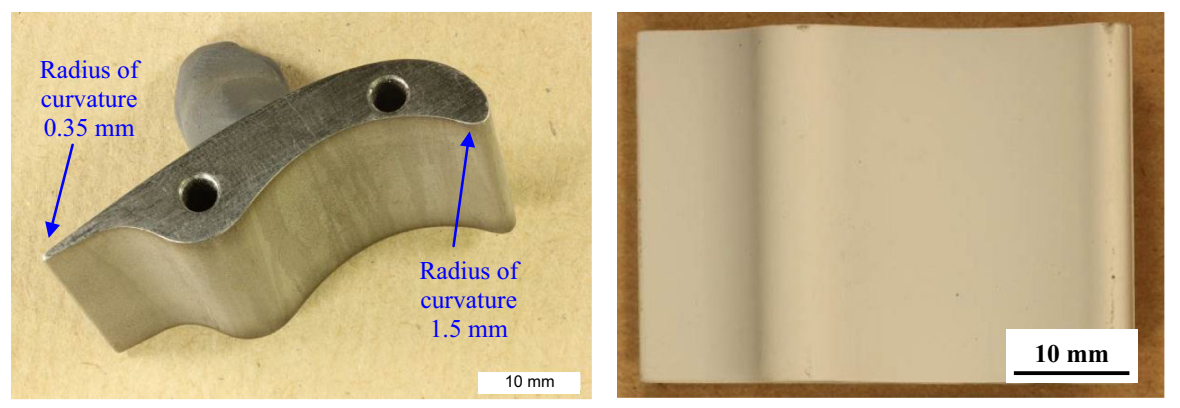

Fig. 1 Photographs of a curved IN6203 test sample before (left) and after (right) coating

pressure plasma sprayed (LPPS) CoNiCrAlY coating; and an APS yttria-stabilizedzirconia (8 wt\% YSZ) TBC. Some of the TBC-coated samples were damaged by impacting the TBC surface with a steel hammer. (At the start a simple drop from a known height was used, but this did not create any defects. An uncontrolled heavy impact had to be used to create visible defects on the surface.) A summary of the coating systems tested is shown in Table 1. Compositions are given in Table 2.

\section{Test Exposures}

Hot corrosion testing of the samples was carried out at Cranfield University. The samples were coated with a deposit of $\mathrm{Na}_{2} \mathrm{SO}_{4}: \mathrm{K}_{2} \mathrm{SO}_{4}$ in the ratio of $4: 1$. This mixture has a melting temperature of $831{ }^{\circ} \mathrm{C}$. A deposit flux of $6.6 \mu \mathrm{g} / \mathrm{cm}^{2} / \mathrm{h}$ was used with the sample being coated with deposit every $100 \mathrm{~h}$. The samples were then exposed to a gaseous environment of 0.7 vol\% $\mathrm{SO}_{2}, 14.6 \mathrm{vol} \% \mathrm{O}_{2}$ and bal. $\mathrm{N}_{2}$ at $850{ }^{\circ} \mathrm{C}$ for $1000 \mathrm{~h}$ (with a thermal cycle every $100 \mathrm{~h}$ to allow the deposit to be reapplied in which the samples were left to cool to room temperature after the furnace was turned off, and the furnace heated at $6{ }^{\circ} \mathrm{C} / \mathrm{min}$ ). At this test temperature, the deposit will be liquid; resulting in type I hot corrosion conditions. Siemens Industrial Turbomachinery Ltd has empirical correlations to link these test conditions to field data.

Curved test samples with LPPS CoNiCrAlY and APS TBC had previously been tested for isothermal and cyclic ( $1 \mathrm{~h}$ dwell at temperature followed by forced air

Table 1 Coating systems tested in the corrosive environment

\begin{tabular}{llll}
\hline Sample type & Base alloy & Bond coat & TBC \\
\hline Flat plate & Haynes 230 & LPPS CoNiCrAlY & \\
Flat plate & Haynes 230 & LPPS CoNiCrAlY & APS YSZ \\
Flat plate & Haynes 230 & LPPS CoNiCrAlY & Damaged APS YSZ \\
Curved & IN6203 & LPPS CoNiCrAlY & \\
Curved & IN6203 & LPPS CoNiCrAlY & APS YSZ \\
Curved & IN6203 & LPPS CoNiCrAlY & Damaged APS YSZ \\
\hline
\end{tabular}


Table 2 Nominal compositions of the substrates and bond coat (wt $\%$ )

\begin{tabular}{lllllllllllll}
\hline & $\mathrm{Ni}$ & $\mathrm{Cr}$ & $\mathrm{Al}$ & $\mathrm{Co}$ & $\mathrm{Mo}$ & $\mathrm{W}$ & $\mathrm{Ti}$ & $\mathrm{Ta}$ & $\mathrm{Nb}$ & $\mathrm{Hf}$ & $\mathrm{Y}$ & $\mathrm{C}$ \\
\hline Haynes 230 & 61.6 & 22.0 & 0.3 & & 2.0 & 14.0 & & & & & & 0.1 \\
IN6203 & 51.6 & 22 & 2.3 & 19 & & 2.0 & 3.5 & 1.1 & 0.8 & 0.8 & & 0.15 \\
CoNiCrAlY & 32 & 21 & 8 & 38.5 & & & & & & & 0.5 & \\
\hline
\end{tabular}

cooling) oxidation in laboratory furnaces in accordance with the Siemens Industrial Turbomachinery Ltd standard TBC lifing assessment. Briefly, this involves thermally degrading samples in isothermal and cyclic furnaces for a range of times and temperatures and assessing how micro-cracking forms within the coating. End of useful life is considered to be when any region of the sample shows microcracking across $20 \%$ of the area examined. The coating was found to meet design requirements. Whilst these samples tested in oxidation were not the primary focus of this investigation, comparisons have been made (between oxidation samples and hot corrosion samples) to highlight differences between the oxides that formed in air and those that formed in a hot corrosion environment.

Details of the test conditions are summarized in Table 3.

\section{Sample Analysis}

After testing, the samples were completely encapsulated in resin. A vacuum impregnation technique was used to ensure the resin fully penetrated open pores in the TBC. Samples were sectioned after the resin had set (to minimize cutting damage) and then ground in stages to remove a further $2 \mathrm{~mm}$ of material from the cutting face. Finally the samples were polished to a $1 \mu \mathrm{m}$ surface finish. This technique is the standard method used to prepare TBC samples to provide design data for Siemens Industrial Turbomachinery Ltd, and ensures preparation damage within the coating is kept to a minimum.

Samples were then characterized using optical microscopy and in a scanning electron microscope (SEM). Measurements of the chemical composition of the oxides were made using energy-dispersive spectroscopy (EDS), although it should be noted that these measurements were only semi-quantitative due to the interaction

Table 3 Test details

\begin{tabular}{|c|c|c|c|c|c|}
\hline $\begin{array}{l}\text { Sample } \\
\text { type }\end{array}$ & Gas & Deposit & $\begin{array}{l}\text { Flux }(\mu \mathrm{g} / \\
\left.\mathrm{cm}^{2} / \mathrm{h}\right)\end{array}$ & $\begin{array}{l}\text { Cyclic/ } \\
\text { 'isothermal' }\end{array}$ & $\begin{array}{l}\text { Temperature } \\
\left({ }^{\circ} \mathrm{C}\right)\end{array}$ \\
\hline $\begin{array}{l}\text { Flat or } \\
\text { curved }\end{array}$ & $\begin{array}{l}0.7 \text { vol\% } \mathrm{SO}_{2}, 14.6 \text { vol } \% \\
\mathrm{O}_{2} \text {, bal. } \mathrm{N}_{2}\end{array}$ & $\begin{array}{l}4: 1 \\
\quad \mathrm{Na}_{2} \mathrm{SO}_{4}: \mathrm{K}_{2} \mathrm{SO}_{4}\end{array}$ & 6.6 & 'Isothermal' & 850 \\
\hline $\begin{array}{l}\text { Curved } \\
\text { only }\end{array}$ & Laboratory air & None & None & 'Isothermal' & 900 \\
\hline $\begin{array}{c}\text { Curved } \\
\text { only }\end{array}$ & Laboratory air & None & None & Cyclic (1 h) & 900 \\
\hline
\end{tabular}


volume of the beam being larger than some of the features (e.g. precipitates) measured.

In certain positions, the thermally grown oxide (TGO) and outer $\beta$-phase depleted region were measured from SEM images. Twenty-six measurements were taken at each position-measurements were made from backscattered electron SEM images at $\times 2000$ magnification and the 26 measurements represent approximately a $0.2 \mathrm{~mm}$ length of TGO. The measurements were then put into ascending order and plotted against measurement number to give an indication of how variable the measurements were.

\section{Results and Discussion}

\section{Results for the Flat Haynes 230 Samples}

At the end of the $1000 \mathrm{~h}$ test none of the APS TBC-coated samples showed visible macro-spallation of the ceramic coating, even those samples where the TBC had been damaged prior to exposure in the hot corrosion environment. Photographs of the postexposure flat plate samples are shown in Fig. 2. Backscattered electron SEM images of sections through the CoNiCrAlY coating are also shown in Fig. 2. The presence of the TBC had reduced the hot corrosion of the CoNiCrAlY, even where the TBC had been pre-cracked (compare Fig. 2e, h to b). The sample with no TBC experienced type I hot corrosion, whereas the samples with TBC formed a stable TGO.

The crack in the aerofoil TBC (Fig. 2g), within the plane of view examined, did not propagate all the way through the TBC to the CoNiCrAlY coating. The crack ran parallel to the CoNiCrAlY interface, 5-50 $\mu \mathrm{m}$ into the TBC. Within the plane examined, the crack parallel to the CoNiCrAlY interface was $\sim 12 \mathrm{~mm}$ in length.

The TGO and $\beta$-denuded layer were measured for the sample with good APS TBC and the sample with the cracked APS TBC and the results are shown in Fig. 3. The TGO, and especially the denuded layer, was thicker on average in the sample with the cracked TBC. Whilst a significant amount of the TGO was of similar thickness between the two samples for the cracked TBC samples, there were more rounded almost pit-like areas of oxide in the damaged sample increasing the TGO thickness in specific locations, as shown in Fig. 4.

Spot EDS analysis was used to assess the chemical composition of the TGO. For the majority of the TGO the composition was very similar between the cracked and non-cracked TBC samples. However, at the edges of the rounded pit-like areas of oxide, there appeared to be small precipitate-like features (Fig. 4). It was not possible to accurately image the precipitate-like features within the resolution of the SEM available. The interaction volume for EDS analysis would have been significantly larger than the precipitates, but analyses from the precipitate-like features showed traces of $\mathrm{S}$ and $\mathrm{Y}$ that were not found when analysing areas next to them.

Whilst the crack through the TBC provided an easier diffusion path for the gaseous atmosphere and/or deposit, it clearly restricted $\mathrm{S}$ diffusion when compared to a CoNiCrAlY without TBC (Fig. 2b). This may be due to liquid deposit penetration being difficult, and hence, reducing the amount of $\mathrm{S}$ that can diffuse 

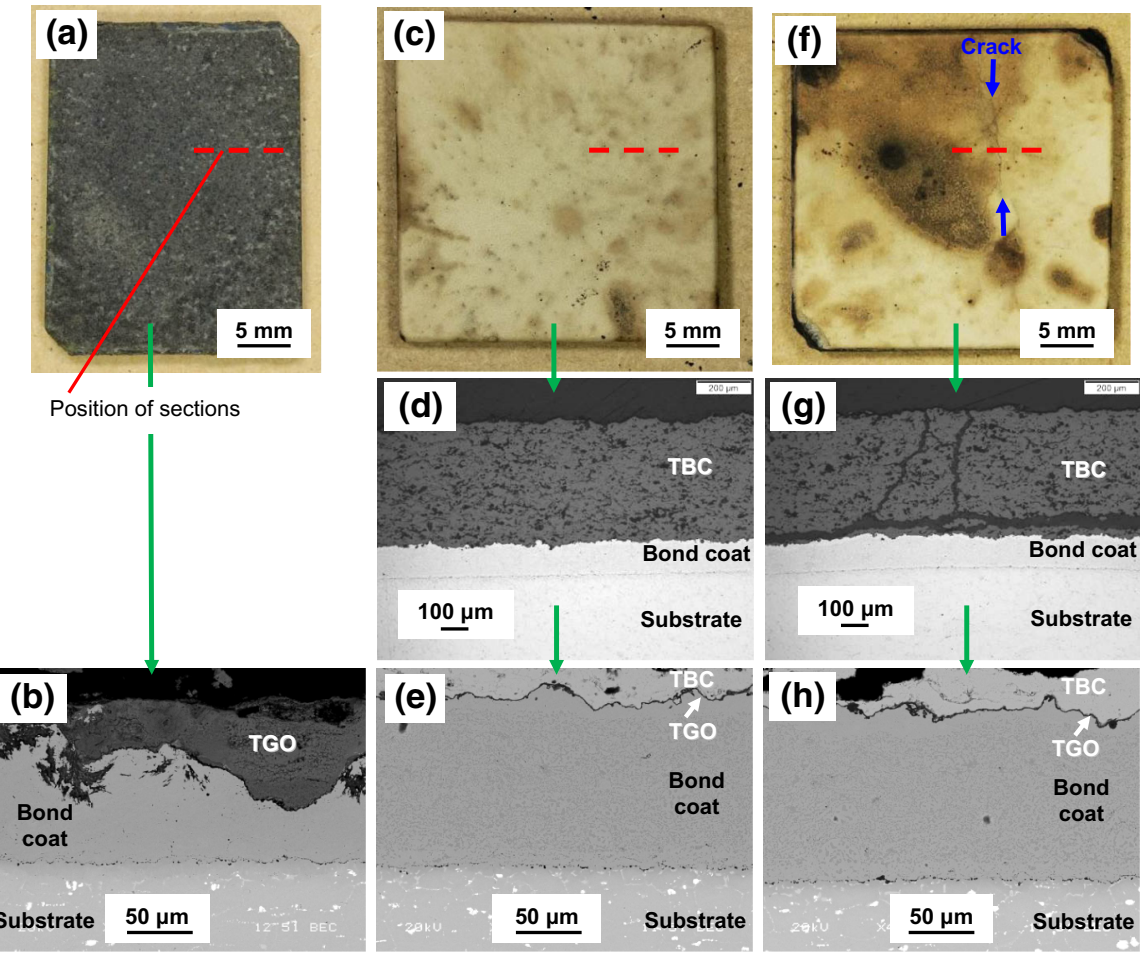

Fig. 2 Photographs and backscattered electron SEM images of a-b the LPPS CoNiCrAlY-coated flat Haynes 230 test piece, photographed after exposure (a) and in cross section in the SEM (b); c-e the LPPS CoNiCrAlY + APS TBC-coated test piece, photographed after exposure (c), in cross-sectional optical microscopy (d) and in cross section in the SEM (e); and $\mathbf{f}-\mathbf{h}$ the LPPS CoNiCrAlY + damaged APS TBC-coated test piece, photographed after exposure (f), in cross-sectional optical microscopy (g) and in cross section in the SEM (h)

through the coating. Where S does penetrate through the TBC, it locally appears to cause an increase in the oxide thickness, but this did not appear to have significantly increased macro-cracking/spallation of the ceramic layer.

\section{Results for the Curved IN6203 Samples}

Backscattered electron SEM images and optical microscope images of the hot corrosion attack of the CoNiCrAlY-coated curved IN6203 test piece are shown in Fig. 5. The level of attack on the $1.5 \mathrm{~mm}$ radius of curvature was similar to that found on the flat sample; however, the level of attack was significantly worse for the $0.35 \mathrm{~mm}$ radius of curvature. This suggests that small radii may exacerbate hot corrosion, potentially as a result of increased scale spallation.

The presence of a TBC again had a beneficial effect on reducing the level of attack of the CoNiCrAlY as shown in Fig. 6. However, there was cracking in the TBC parallel to the CoNiCrAlY/TBC interface at both the $1.5 \mathrm{~mm}$ radius of curvature and $0.35 \mathrm{~mm}$ radius of curvature regions of the sample, even for the 


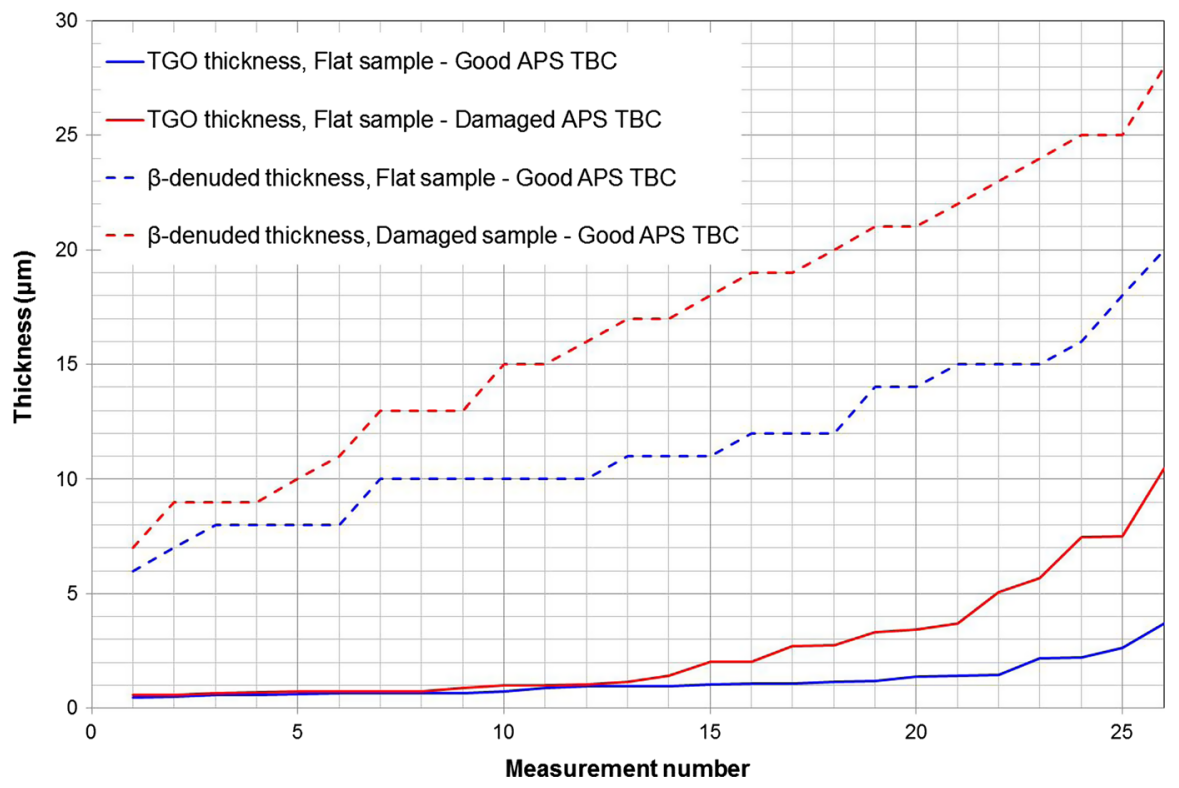

Fig. 3 Graph showing the range in thickness measurements (from the lowest recorded to the highest) for the TGO and $\beta$-denuded layer for the flat sample with good APS TBC and flat sample with a damaged APS TBC
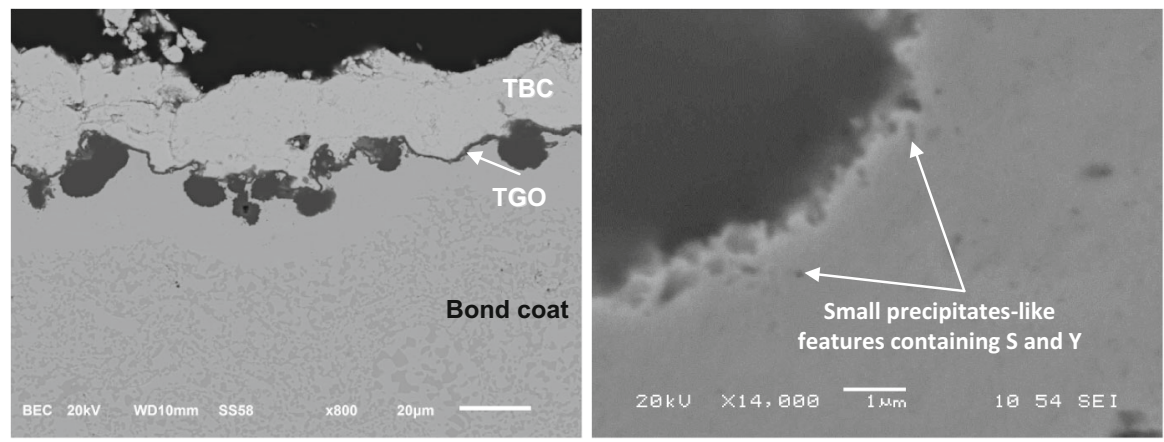

Fig. 4 Backscattered electron SEM images of the TGO on the flat sample with the cracked TBC, showing an area with rounded pit-like areas in the TGO. Small precipitate-like features containing $\mathrm{S}$ and $\mathrm{Y}$ were found associated with the rounded pit-like areas of oxide

sample that was nominally coated with a 'good TBC'. Typically, in oxidation testing the $0.35 \mathrm{~mm}$ radius of curvature will fail first, followed by the $1.5 \mathrm{~mm}$ radius of curvature sample, but usually after much longer times. For comparison, Fig. 6 also shows images from a sample after $1000,1 \mathrm{~h}$ cycles at $900{ }^{\circ} \mathrm{C}$ in laboratory air-this oxidized sample did not show any cracking within the TBC.

Examples of the TGO at the $1.5 \mathrm{~mm}$ radius of curvature for the $850{ }^{\circ} \mathrm{C}$ corroded sample and the $900{ }^{\circ} \mathrm{C}$ thermally cycled in air sample are shown in Fig. 7. The TGO was visually thicker and more uniform in the oxidized sample (no cracks formed), 

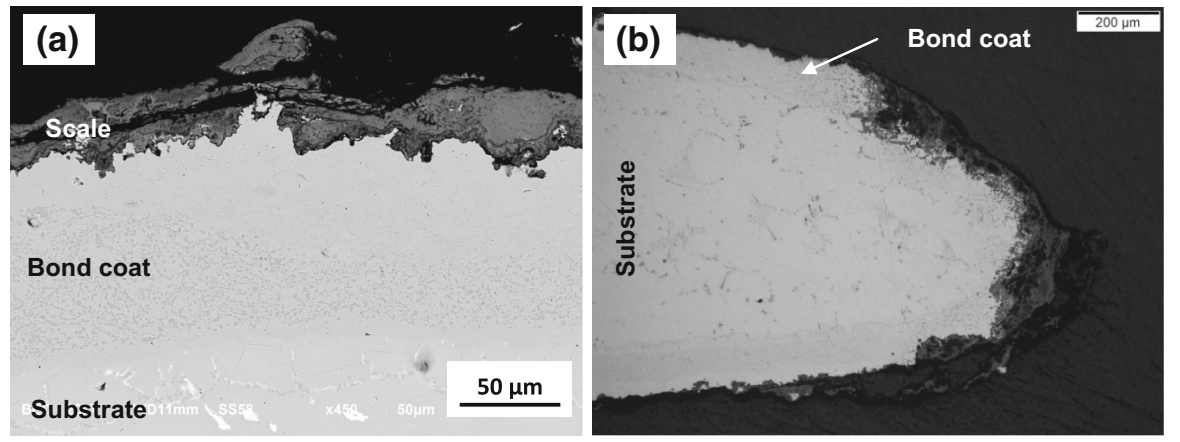

Fig. 5 a Backscattered electron SEM image of the hot corrosion on the $1.5 \mathrm{~mm}$ radius of curvature, and b optical microscope image of the hot corrosion on the $0.35 \mathrm{~mm}$ radius of curvature
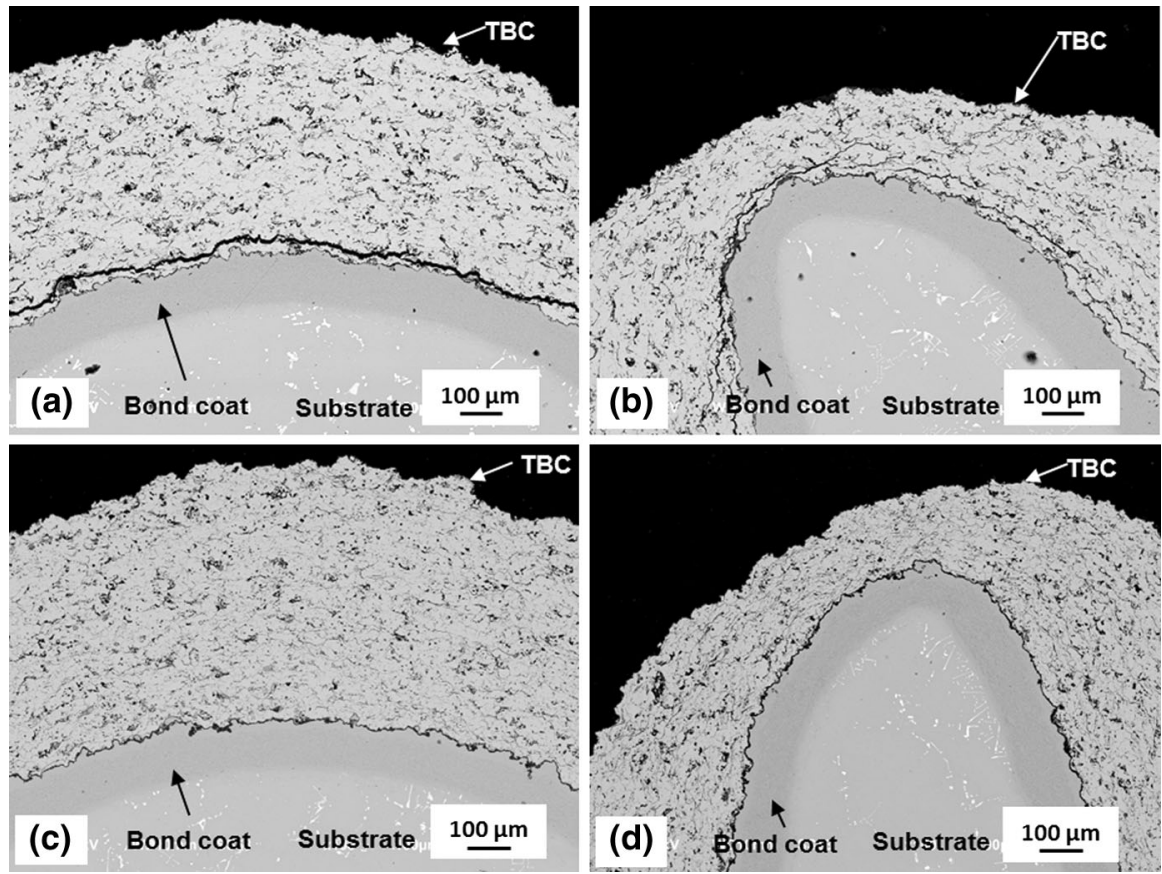

Fig. 6 Backscattered electron SEM images of a $1.5 \mathrm{~mm}$ radius of curvature and $\mathbf{b} 0.35$ mm radius of curvature after exposure to a hot corrosion environment at $850{ }^{\circ} \mathrm{C}$ for $1000 \mathrm{~h}$, and c $1.5 \mathrm{~mm}$ radius of curvature and d $0.35 \mathrm{~mm}$ radius of curvature after cyclic oxidation testing at $900{ }^{\circ} \mathrm{C}$ for $1000 \mathrm{~h}(1 \mathrm{~h}$ cycles)

but thinner with occasional thick areas (and potentially more mixed oxides) in the corroded sample (where delamination cracks had formed). Measurements of TGO thickness are shown in Fig. 8, and this confirmed that the oxide was thinner in the corroded sample where cracking had occurred. 


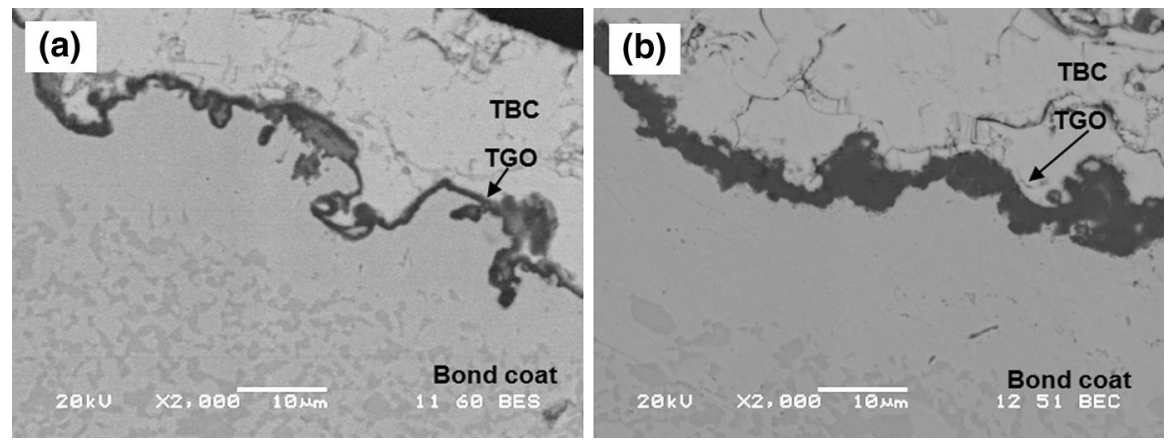

Fig. 7 Backscattered electron SEM images of the TGO for a the sample with a good APS TBC corroded for $1000 \mathrm{~h}$ at $850{ }^{\circ} \mathrm{C}\left(10\right.$ thermal cycles), and b a sample thermally cycled in air for $1000 \mathrm{~h}$ at $900{ }^{\circ} \mathrm{C}$ (1000 cycles)

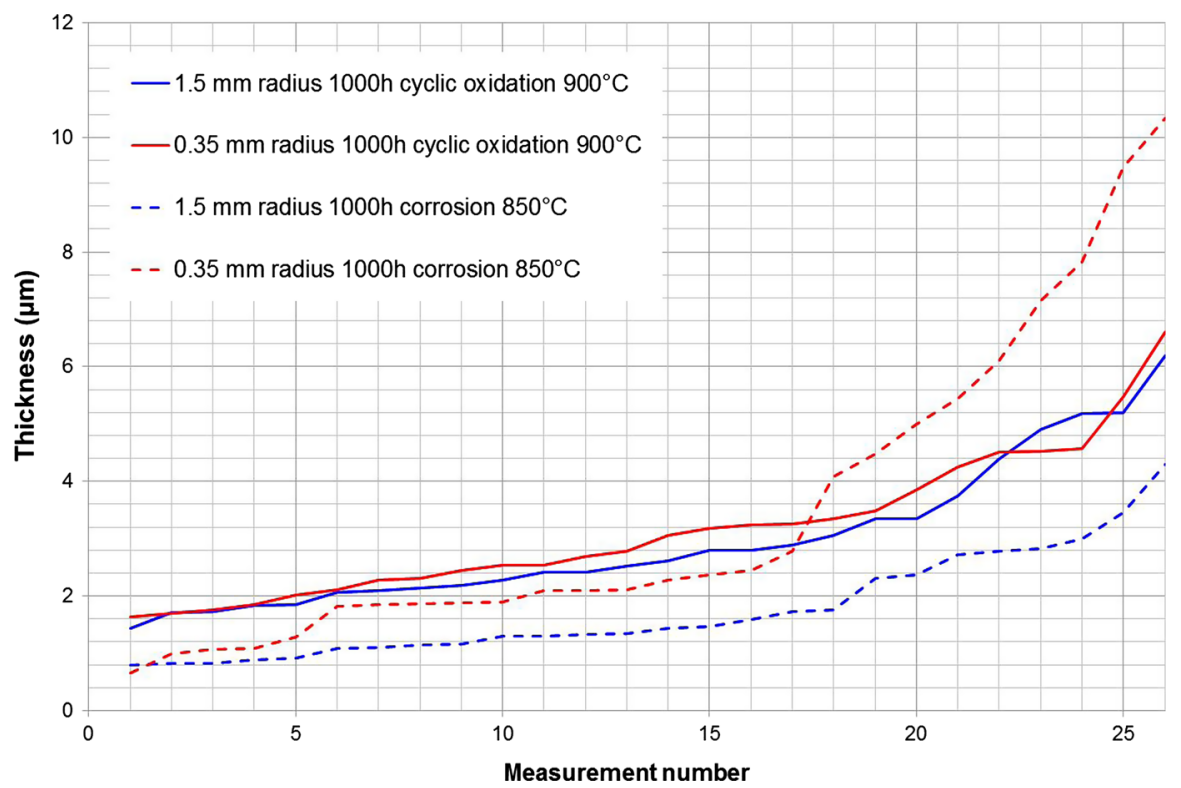

Fig. 8 Graph showing the range in thickness measurements (from the lowest recorded to the highest) for the TGO for the $1.5 \mathrm{~mm}$ and $0.35 \mathrm{~mm}$ radius of curvature for a sample corroded at $850{ }^{\circ} \mathrm{C}$ for $1000 \mathrm{~h}$ and a sample thermally cycled in air at $900{ }^{\circ} \mathrm{C}$ for $1000 \mathrm{~h}$

The curved IN6203 sample that had been damaged prior to exposure showed cracking through the thickness of the TBC at the $1.5 \mathrm{~mm}$ radius of curvature area, and delamination cracks parallel to the NiCoCrAlY/TBC interface. In this area the TGO was again found to be thicker than for the sample that had not been damaged, but there was no macro-spallation of the TBC. 


\section{Discussion}

The life of an APS TBC is reported to be reduced as the radius of curvature of a sample/component reduces, and some coating life models take this into account [5]. The data from Viswanathan et al. [5] suggests that the radii on the test samples in this work should experience a $70 \%$ reduction in life compared to the remainder of the sample. Although there was no actual spallation of TBC, the coating in the regions with 1.5 and $0.35 \mathrm{~mm}$ radii was considered to be at the end of life due to $>20 \%$ micro-cracking in those areas. Hence, a life can be inferred and, based on test to turbine correlations, the results provide some supporting evidence that the use of APS TBCs in corrosive environments may be acceptable. However, the fact that the samples exposed in a corrosive environment had cracked, whereas those exposed to air (albeit at a higher temperature) had not, suggests that there was a debit on life due to the corrosive atmosphere.

TBC spallation is often considered to occur due to stresses in the ceramic layer as a result of the growth (thickening) of the TGO; with the amount of cracking likely to increase as the TGO thickness increases [6]. Thermal cycles are also often reported to increase the propensity for cracking/spallation [7]. In this work the sample exposed in a corrosive atmosphere developed micro-cracks with a thinner TGO (on average) and fewer thermal cycles than a sample exposed in air. This suggests that stresses due to coarsening of the TGO are unlikely to be the dominant mechanism of failure unless the periodic thicker areas of TGO created sufficient localized high stress regions to cause micro-cracks to form and then link up.

Another mechanism referred to in the literature relates to destabilization of the YSZ leading to the formation of the monoclinic YSZ phase, which undergoes a phase change during thermal cycling [3,8]. However, the literature suggests that an active phase such as $\mathrm{V}$ is required for this to occur and that in the presence of $\mathrm{Na}_{2} \mathrm{SO}_{4}$ alone destabilization does not occur. It is unclear whether the $\mathrm{K}_{2} \mathrm{SO}_{4}$ addition that lowers the melting point of the deposit would be active enough to destabilize the TBC and further work should be carried out to properly eliminate this as a mechanism; however, the $\mathrm{K}$ was not detected in a significant level at any position within the TBC or the TGO.

EDS analysis showed minor levels of $\mathrm{Na}$ (up to $0.4 \mathrm{wt} \%$ ) and $\mathrm{S}$ (up to $0.6 \mathrm{wt} \%$ ) in the TGO on the sample exposed to a hot corrosion atmosphere, but not in the sample exposed to air. This suggests that some level of $\mathrm{Na} / \mathrm{S}$ managed to diffuse through the APS TBC, potentially along micro-cracks. Similar transport of Na and S was also reported by Jones [3]. The $\mathrm{Na}$ and $\mathrm{S}$ could explain the occurrence of the mixed oxides/occasional thicker TGO areas. (Temperature may also have an effect with oxidation at lower temperatures promoting the formation of mixed oxides as well as alumina; however, Nalin [9] showed that mixed oxides would be equally likely to form at both 850 and $900{ }^{\circ} \mathrm{C}$ in air, which suggests that the difference observed in this work is most likely due to the corrosive environment.)

Another potential mechanism is that if the $\mathrm{Na} / \mathrm{S}$ had diffused along the microcracks, it may have promoted the sintering of micro-cracks together. This could have reduced the compliance of the ceramic layer, leading to a higher stress in the TBC from a thinner TGO. It was not possible to quantitatively show any $\mathrm{Na}$ or $\mathrm{S}$ 

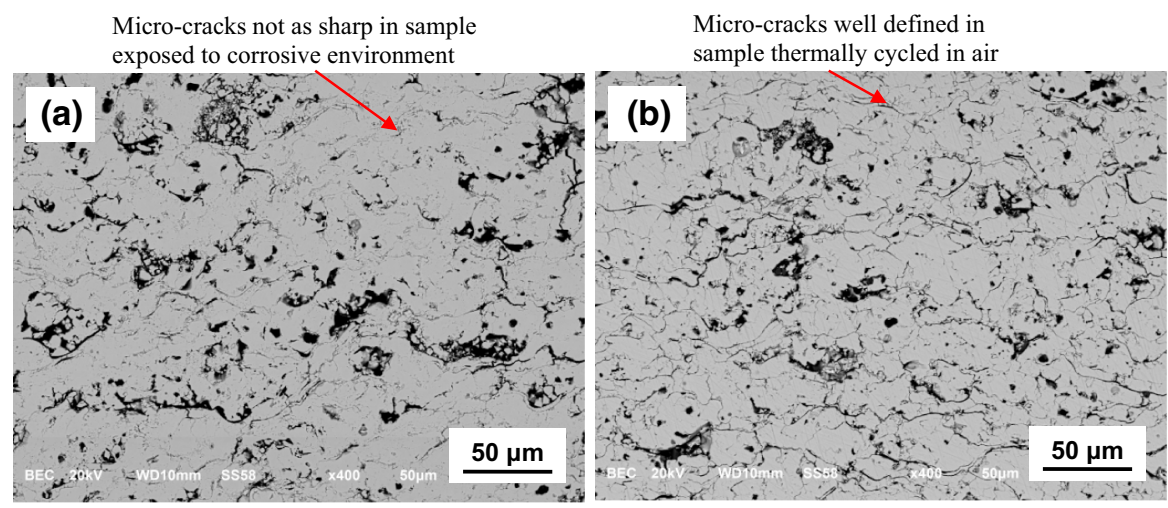

Fig. 9 Backscattered electron SEM images of the TBC from a the sample corroded at $850{ }^{\circ} \mathrm{C}$ for $1000 \mathrm{~h}-$ micro-cracks less defined, and $\mathbf{b}$ a sample thermally cycled in air at $900{ }^{\circ} \mathrm{C}$ for $1000 \mathrm{~h}-$ microcracks more defined

within the ceramic layer, or a reduction in porosity; however, qualitatively the backscattered electron SEM images in Fig. 9 appear to show that the micro-cracks are less pronounced in the corroded sample.

Although the exact mechanism for the formation of delamination cracks on the samples exposed to a hot corrosion environment is unknown, the position of the first delamination cracks is similar to that found for isothermal and cyclic oxidation samples. This suggests that an empirical life debit factor could be developed for standard $8 \mathrm{wt} \%$ YSZ TBC in corrosive environments. However, more samples would need to be tested to provide additional data points for the effects of $\mathrm{SO}_{2}$ level and deposit flux. The presence of cracks through the thickness of the TBC resulted in an increase in TGO growth, but no macro-delamination of the TBC. Ultimately the presence of cracks ought to lead to a slight reduction in TBC life (as it is likely that the stress in the TBC would be higher due to a thicker TGO), and this again could be represented as a TBC life debit factor.

\section{Conclusions}

Further to exposing the APS TBC-coated samples to a type I hot corrosion environment for $1000 \mathrm{~h}$, a range of observations were made. Some supported current understanding of corrosion, such as:

- The very tight radius on the curved sample appeared to exacerbate the hot corrosion attack of the CoNiCrAlY bond coat.

- The APS TBC significantly reduced the hot corrosion rate of the CoNiCrAlY bond coat.

Other key observations included: 
- Cracking through the thickness of the TBC resulted in a slight increase in TGO thickness, but did not lead to major spallation of the TBC within the duration of the current tests.

- Delamination cracking occurred on the 1.5 and $0.35 \mathrm{~mm}$ radii of curvature areas on the curved test samples at a thinner average TGO thickness under type I conditions than would be expected to give cracking in isothermal or cyclic oxidation testing.

This has implications for the operation of gas turbines where TBCs are present. In particular, damage to the outer TBC layer does not appear to be immediately catastrophic for the bond coat below, although the severity may be dependent upon the underlying curvature and hence how rapidly the TBC could be expected to shed.

Finally, this work suggests that a debit factor could be developed to predict the spallation life of APS TBCs in corrosive environments, with or without cracking. Such a debit factor would require the testing of more samples, to provide relationships for how $\mathrm{SO}_{2}$ level and deposit flux may affect micro-cracking.

Open Access This article is distributed under the terms of the Creative Commons Attribution 4.0 International License (http://creativecommons.org/licenses/by/4.0/), which permits unrestricted use, distribution, and reproduction in any medium, provided you give appropriate credit to the original author(s) and the source, provide a link to the Creative Commons license, and indicate if changes were made.

\section{References}

1. R. C. Reed, The Superalloys Fundamentals and Applications, (Cambridge University Press, Cambridge, 2006), pp. 18-25.

2. G. Y. Lai, High-Temperature Corrosion and Materials Applications, (ASM International, 2007), pp. 249-258.

3. R. L. Jones, J. Therm. Spray Technol. 6, (1), 77-84 (1997).

4. H. Zhao, C. G. Levi and H. N. G. Wadley, Surf. Coat. Technol. 251, 74-86 (2014).

5. R. Viswanathan, D. Gandy, K. Krzywosz, S. Cheruvu and E. Wan, Combustion Turbine (CT) Hot Section Coating Life Management. D of E project DE-FC26-01NT41231 Semi Annual Report (2002). http://www.osti.gov/scitech/servlets/purl/812125.

6. S. Bose, High Temperature Coatings, (Elsevier, Oxford, 2007), pp. 162-183.

7. A. G. Evans, D. R. Mumm, J. W. Hutchinson, G. H. Meier and F. S. Pettit, Prog. Mater. Sci. 46, 505-553 (2001).

8. P. Bajpai, A. Das, P. Bhattacharya, S. Madayi, K. Kulkarni and S. Omar, Hot corrosion of stabilized zirconia thermal barrier coatings and the role of Mg inhibitor. J. Am. Ceram. Soc. 98, (8), 2655-2661 (2015).

9. L. Nalin, Degradation of environmental protection coatings for gas turbines. Ph.D. Thesis, Cranfield University (2008). 